\title{
Neurogenesis and neuroprotection in postischemic brain neurodegeneration with Alzheimer phenotype: is there a role for curcumin?
}

\author{
Ryszard Pluta ${ }^{1}$, Anna Bogucka-Kocka ${ }^{2}$, Marzena Ułamek-Kozioł ${ }^{1}$, Wanda Furmaga-Jabłońska ${ }^{3}$, \\ Sławomir Januszewski ${ }^{1}$, Judyta Brzozowska ${ }^{4}$, Mirosław Jabłoński ${ }^{5}$, Janusz Kocki ${ }^{6}$ \\ ${ }^{1}$ Laboratory of Ischemic and Neurodegenerative Brain Research, Mossakowski Medical Research Centre, Polish Academy \\ of Sciences, Warsaw, ${ }^{2}$ Department of Pharmaceutical Botany, Medical University of Lublin, ${ }^{3}$ Department of Neonate \\ and Infant Pathology, Medical University of Lublin, ${ }^{4}$ Department of Clinical Psychology, Medical University of Lublin, \\ ${ }^{5}$ Department of Rehabilitation and Orthopaedics, Medical University of Lublin, ${ }^{6}$ Department of Clinical Genetics, \\ Medical University of Lublin, Lublin, Poland
}

\begin{abstract}
For thousands of years, humankind has used plants for therapeutics. Nowadays, there is a renewed public interest in naturally occurring treatments with minimal toxicity and diets related to health. Alterations in hippocampal neurogenesis have been recognized as an integral part of brain ischemia. Neuronal stem/progenitor cells in the hippocampus are positively and negatively regulated by intrinsic and extrinsic agents. One positive regulator of neurogenesis in the hippocampus is curcumin in the diet. This review provides an assessment of the current state of the field in hippocampal neurogenesis and neuroprotection studies in brain ischemia and focuses on the role of curcumin in the diet. Data suggest that dietary intake of curcumin enhances neurogenesis. Recent studies performed in ischemic models have suggested that curcumin also has neuroprotective features. One potential mechanism to explain several of the general health benefits associated with curcumin is that it may prevent ageing-associated changes in cellular proteins that lead to protein insolubility and aggregation after ischemia such as $\beta$-amyloid peptide and tau protein. Here, we also review the evidence from ischemic models that curcumin improves cognition and health span by overexpression of life supporting genes and preventing or delaying the onset of neurodegenerative changes. Available data provide evidence that curcumin induces neurogenesis and neuroprotection and may provide a novel therapeutic agent for both regenerative medicine and for the treatment of neurodegenerative diseases such as postischemic brain neurodegeneration with Alzheimer phenotype.
\end{abstract}

Key words: brain ischemia, neurodegeneration, dementia, neurogenesis, neuroprotection, curcumin.

Communicating author:

Prof. Ryszard Pluta, MD, PhD, Laboratory of Ischemic and Neurodegenerative Brain Research, Mossakowski Medical Research Centre, Polish Academy of Sciences, 5 Pawińskiego St., 02-106 Warsaw, Poland, phone: +48 22 6086-540 or 6086-469, fax: +48 22 668 55 32, e-mail: pluta@imdik.pan.pl 


\section{Introduction}

Age-related disorders such as Alzheimer's disease and brain ischemia represent a major clinical problem in developed countries $[18,28,41]$ and are a major economic burden for health care systems $[15,37]$. Dietary, genetic and molecular factors are important determinants in progression and treatment of the above diseases [1,47-51,53]. In developed countries ischemic stroke is a major cause of physical disability, the third leading cause of mortality and the second most common cause of dementia [28,41]. In a population of 1 million people 2.4 thousand individuals will have a stroke each year, of whom less than $50 \%$ will be independent 1 year later [28]. Numerous self-governing survivors have lasting physical and/or cognitive deficits and/or behavioral abnormalities which can affect family life and have a significant professional cost. An overarching consequence of ischemic brain injury is both short- and long-term cognitive deficits. These deficits typically occur in attention, memory, learning and higher order executive functions $[3,24,29]$. Cognitive deficits after ischemia can be attributed to damage to certain vulnerable brain regions including the hippocampus [47] and temporal cortex [42], as well as sub-cortical white matter tracts $[44,45]$. The hippocampus, which is crucial for declarative memory formation, demonstrates atrophy $[43,46,47]$. Postischemic dementia is one of the main causes of dependency in survivors. An enormous rise in the occurrence and problem of postischemic dementia is likely to happen because of the drop in mortality following brain ischemia and ageing of populations. Finally, global hippocampal neuronal loss with atrophy, temporal lobe atrophy and white matter changes are hallmarks of postischemic dementia $[28,50]$. Even when the above factors do not lead to dementia by themselves, their cumulative effect can reach the threshold of changes required to develop dementia. The prevalence of postischemic dementia is likely to increase in the near future because of better survival following brain ischemia and ageing of the population. Recognition of these patients is important because they have higher mortality, are frequently functionally damaged and need treatment. Studies should now focus on delineation of the goal of postischemic cognitive decline without dementia, which could be a preliminary stage of postischemic dementia and is much more frequent in clinical practice. Brain ischemia like Alzheimer's dis- ease is a neuropathological condition accompanied by neuroinflammation and immune system changes $[33,46,64,72]$. One minute of brain ischemia is estimated to destroy approximately 2 million neurons and 14 million synapses [57].

$\beta$-amyloid peptides derived from amyloid precursor protein via $\beta$-secretase and $\gamma$-secretase cleavage are characteristic for postischemic brain neurodegeneration in animals and humans $[52,53,55]$. Oxidative stress mediates $\beta$-amyloid peptide neurotoxicity, and the latter contributes to neuronal death following brain ischemia [52]. Along with $\beta$-amyloid peptide, tau protein changes in neuronal microtubules also contribute to the postischemic neurodegeneration in adult animals $[68,70]$. Abnormal phosphorylation and aggregation of tau protein lead to postischemic neuronal dysfunction [70]. These data provide a neuropathological basis for dementia development in animals and patients following a postischemic episode. Failed clearance of $\beta$-amyloid peptide resulting from impaired autophagy may also contribute to postischemic neurodegeneration [65].

Apolipoprotein A1, E and J can influence the structure, toxicity and accumulation of the $\beta$-amyloid peptide in the postischemic brain $[52,53,55]$. Apolipoproteins may also be involved in $\beta$-amyloid peptide metabolism prior to its deposition. Additive effects of apolipoproteins on $\beta$-amyloid peptide deposition may play an important role in regulating extracellular $\beta$-amyloid peptide accumulation independent of $\beta$-amyloid peptide synthesis. The above data indicate that apolipoprotein A1, E and J accumulation after ischemia may represent a secondary injury factor that could exacerbate the healing of ischemic neurons and the outcome [52,53]. Extracellular apolipoprotein deposition was noted mainly following neuronal death. Transient brain ischemia led to changes in the presynaptic protein $\alpha$-synuclein in the hippocampus $[52,53]$. Strong $\alpha$-synuclein staining was observed in the hippocampus CA1 sector with postischemic long-term survival. Abnormal $\alpha$-synuclein deposition might impair synaptic function, resulting in memory problems and additional postischemic neuronal death. Thus, the induction of amyloid precursor protein, apolipoproteins, presenilins and other Alzheimer's disease-related genes and proteins after ischemia may be the molecular link between Alzheimer's disease pathways and ischemia-reperfusion neurodegeneration [51,53]. As an effect of induction of the above genes there was 
noted long-term abnormal co-accumulation of amyloid precursor protein and amyloid precursor protein cleaving enzymes [52]. The concentration of these proteins may lead to amyloid precursor protein proteolysis and $\beta$-amyloid peptide formation with final extracellular deposition as plaques [52,55]. Summing up, experimental data on postischemic brains show that Alzheimer's disease-related changes render the brain more susceptible to ischemic damage and in consequence lead to the development of Alzheimertype dementia [3,24,29].

Old age is associated with enhanced susceptibility to ischemic stroke and poor recovery from postischemic injury, but the cellular mechanisms which trigger these phenomena are only partially understood $[30,46,52-54,68,70]$. Therefore, studying the complex processes underlying postischemic recovery of structural and cognitive functions in individuals a long time after birth is of considerable clinical importance [54]. Cognitive and morphological analysis of aged brain after ischemia in animals shows that: first, behaviorally they are more severely impaired and they show diminished functional recovery; second, they have a larger amount of apoptotic neurons and a higher degree of cellular disintegration; third, macrophages and astrocytes are activated early and strongly in the postischemic period; fourth, the early, powerful proliferation of glial cells leads to the precipitous development of scar tissue, enlarged by the chronic deposition of neurotoxic C-terminal of amyloid precursor protein; and fifth, the timing of the regenerative genetic response and cellular capability of the brain is altered and mechanisms are dysregulated and reduced, thereby additionally compromising functional recovery $[30,44,54]$. Whether endogenous neurogenesis is a factor that contributes to spontaneous recovery after ischemia has not yet been established. If the development of new neurons from endogenous stem cells is to become an effective treatment for postischemic neurodegeneration after birth, we need to more completely understand the factors that promote neurogenesis and how those factors change in later life. If neurogenesis from endogenous neuronal stem cells is to be used therapeutically, an individual approach will be required to assess the possible extent of the neurogenic response as well as the possibilities to alter this response for functional improvement or prevention of pathological neurogenesis with formation of improper synaptic junctions. The above alterations of hippocampal neurogenesis constitute a possible therapeutic target after ischemia. This endogenous self-repair mechanism may be further enhanced by extrinsic agents, one of which is curcumin in the diet.

There are a few clinically active therapies available for postischemic neurodegeneration, but no regenerative therapy exists currently. A few clinically active, yet not fully effective, therapies such as acetylsalicylic acid, statins and tissue type plasminogen activator are available for ischemic stroke $[17,35,36]$. In the wake of this neurodegenerative pathology, with limited medical therapies, alternative treatments are required which can control the progression of postischemic neurodegeneration. All the neurodegenerative diseases have common mechanisms of neuropathogenesis which include genetic alterations, protein and mitochondrial dysfunction, oxidative stress, cytokine changes and neuroinflammation $[46,52,53]$. Current research has shown that dietary polyphenols target the molecular changes of neurodegeneration with their ability to cross the blood-brain barrier as they control neuronal disease pathways at a molecular level by targeting these common features of neurodegeneration [14]. Polyphenols naturally occur e.g. in vegetables, fruits and red wines, exhibiting neuroprotective properties $[4,40]$. Dietary polyphenols are also involved in prevention of oxidative damage and human LDL oxidation [21,61]. Our analysis briefly outlines the therapeutic role of polyphenols such as curcumin in preventing the development of postischemic neurodegeneration with Alzheimer phenotype based on the most recent literature. We present the change of curcumin from a long-established spice and food coloring to a natural regulator of life processes.

\section{The importance of hippocampal neurogenesis in postischemic brain neurodegeneration}

Ischemic stroke is generally an age-related acute arterial disorder causing loss of neuronal and glial cells, with final development of functional and cognitive deficits. Apart from thrombolysis during the first hours, which can be given only to a small percentage of patients, no effective regenerative treatment to improve functional recovery exists in the postischemic period $[17,35,36]$. The persistence of neural stem cells and neurogenesis in the brain after birth, first suggested in 1912 [2], is accepted now. This change is based mostly on facts accumulated recently, indi- 
cating that neural stem/progenitor cells occupy two main regions, the subventricular zone of the lateral ventricles and the subgranular zone of the dentate gyrus in the hippocampus, where they give rise to neurons after birth $[30,38,54,58]$. Neurogenesis has been found in these brain areas in all mammalian species, including humans $[9,30,38,54,58]$, and may serve to replace brain cells damaged by insults. Two discrete brain regions presented contain progenitor cells that are capable of differentiating into neuronal or glial cells. Current research shows that neurogenesis can be modified by a variety of factors, including stress, neurohormones, growth factors, neurotransmitters and also stroke pathology [30]. In particular, hippocampal neurogenesis may play a role in modulation associated with neuropathology, such as cognitive disorders [38]. The stimulated neurogenesis at sites of brain damage may represent an attempt by the brain at self-regeneration after ischemia. Present research strongly focuses on the questions whether neurogenesis replaces lost and/or dying cells, and if so, to what extent.

Neural stem/progenitor cells could potentially be used to develop regenerative treatments to bring back the function of the postischemic hippocampus. Two major neural stem/progenitor cell-based tactics are currently being explored in experimental models: first, to deliver neural stem/progenitor cells locally or systemically in the brain where they act as stimulators of neurogenesis; and second, to replace diseased neurons and restructure neuronal network by stimulation of endogenous self-neurogenesis [31]

One of the earliest affected brain structures in brain ischemia is the hippocampus, which is involved in the formation and consolidation of memory $[46,53]$. The subgranular zone of the hippocampus dentate gyrus constitutes one of the only two neurogenic zones of the mature brain. Neurogenesis there is a process of generating neurons from neuronal progenitor cells. In the subgranular zone, these neurons proliferate and give rise to immature cells which migrate into the granule cell layer, mature, and integrate into the preexisting network by receiving inputs from the entorhinal cortex and extending projections into the hippocampus CA3 area [71].

Since neurogenesis is required for memory and learning, and its activity has shown to be decreased after ischemia in humans and rodents $[25,26]$, it has been suggested that impaired hippocampal neurogenesis might be an integral part of postischemic progression [58]. Particularly, a variety of key factors involved in brain ischemia, among them presenilin 1 and 2, amyloid precursor protein and its products $\beta$-amyloid peptides, play either a positive or a negative role in hippocampal neurogenesis [7,27]. Furthermore, several growth factors, such as brain-derived neurotrophic factor (BDNF), fibroblast growth factor and vascular endothelial growth factor, have been reported to be upregulated in the neighborhood of $\beta$-amyloid peptide deposits $[6,60]$. These factors are also known to be potent stimulators of neural stem/progenitor cell activity. On the other hand, neuroinflammation and microglia activity that are associated with $\beta$-amyloid peptide store [43], and represent events in the postischemic brain [46], have been demonstrated to reduce neurogenesis [5].

So far, it has not been resolved when and what triggers hippocampal neurogenesis impairment in the postischemic brain. A long-term study attempting to investigate neurogenesis was performed to assess ischemic neurogenic activity [58]. Moreover, numerous aspects of hippocampal neurogenesis, differentiation, and survival of neurons have not been uniformly addressed in the above studies, preventing straightforward comparisons. Nevertheless, animal models will improve our understanding of the hippocampal neurogenesis after ischemia and point out still unresolved issues which demand further investigation.

\section{The role of hippocampal neurogenesis in postischemic brain neurodegeneration}

It has been suggested that an increase in hippocampal neurogenesis might serve as a replacement mechanism for neuronal loss, thereby slowing down postischemic progression to dementia $[24,58]$. However, the native increase in hippocampal neurogenesis might not be sufficient to compensate for the massive ischemic neuronal loss $[26,30,58]$. Recently, $\beta$-amyloid peptide oligomers have been reported to promote the generation of new neurons, but with no effect on cell survival [32]. On the other hand, $\beta$-amyloid peptide injection into the hippocampus in adult mice reduced progenitor cell activity [76] and led to the development of dementia in an animal model of brain ischemia [29]. Therefore, many questions regarding postischemic hippocampal neurogenesis remain open, among them the aspect of timing after ischemia. Neurogenesis in the hippocampus is regulated by numerous elements, including neuropathological conditions such as ischemic 
episodes and diet $[11,30]$. Given that dietary factors have been proved to change the time course after ischemic neurodegeneration [66,77], and the same factors have been shown to modulate neurogenesis in the hippocampus [59], it is possible that the effects of diet on postischemic neurodegeneration are mediated by modulation of hippocampal neurogenesis. Additionally, dietary habits are an important component of lifestyle, which is recognized as one of the ischemic risk factors. To our best knowledge, amongst the current reviews concerning postischemic hippocampal neurogenesis [30,54], diet and brain ischemia and diet and postischemic hippocampal neurogenesis, our review is the first to put together neurogenesis in the hippocampus and postischemic brain neurodegeneration through the effects of dietary influence on both phenomena, in this manner providing a unique and new perspective on the state of postischemic hippocampal neurogenesis. Given that these days there are no effective therapies for postischemic brain neurodegeneration, and no regenerative therapy exists $[17,35,36]$, dietary intervention may be an option to help delay disease progression.

\section{Potent neurogenic activity of curcumin in hippocampus}

Dietary content is important for the positive influence on neurogenesis and subsequent hippocampus mediated cognitive ability. Dietary polyphenols are known to have a beneficial influence on the brain by protecting neuronal cells against injury. For example, curcumin is a natural phenolic component obtained from the plant Curcuma longa, and it has been used in India to treat disorders associated with inflammation and oxidative stress [16]. Curcumin is used as a spice and coloring in foodstuffs with its characteristic yellow color. Due to its yellow color, curcumin is systematically used for coloring e.g. mustard, canned fish and dairy products [13]. Health benefits of curcumin may be limited in view of the fact of its low oral accessibility. On the other hand, due to its lipophilicity curcumin can cross the blood-brain barrier and can reach brain tissue at a functional pharmacological level $[13,14,63]$. The highest curcumin level in the brain tissue is reached approximately $60 \mathrm{~min}$ following intravenous and/or intraperitoneal injection of $100 \mathrm{mg} / \mathrm{kg}$ body weight curcumin in animals [13]. As a consequence of curcumin's immediate metabolism, it is not detectable in the brain after $2 \mathrm{~h}$ [13].
It should be remarked that curcumin can probably attain a therapeutic level in the brain tissue when it is taken on a regular basis [12]. In the above situation curcumin accumulates intracellularly and/or influences epigenetic regulation of gene expression such as DNA methylation and miRNA expression.

In recent years the focus on curcumin has been shifted to its influence on cognition alterations. Clinical data have shown that regular curcumin supplementation improves cognitive function [12]. Additionally, curcumin administration in various animal models of memory impairment reverses memory deficits [12]. These outcomes may be due to curcumin's effects on oxidative stress, BDNF and extracellular signal-regulated kinase (ERK)/P38 signaling pathways and degradation of PKC $\delta$ [12].

It was found that curcumin's anti-inflammatory and antioxidant therapeutic activities reversed $\beta$-amyloid peptide-induced cognitive deficits and neuropathological alterations [16]. Recently, it was reported that curcumin supports impaired hippocampal neurogenesis $[69,73]$. Curcumin has biphasic effects on neural stem/progenitor cells, whereby a low concentration modulates cell proliferation and a high concentration is neurotoxic [69]. This is in agreement with the finding that a high concentration of curcumin induces oxidative stress and triggers apoptosis in cells $[39,69]$. Previous data indicated that the neural stem/progenitor cells' specific mitogenic action of low concentration curcumin is mediated by the activation of ERK and p38 MAP kinases [39]. All considered, the dose-dependent neurogenic activity of curcumin resembles the hormesis theory of curcumin. The hormesis dose consequence phenomenon is characterized by low dose activation and high dose inhibition. In one study, the administration of curcumin significantly increased the number of new neurons in the hippocampus dentate gyrus by stimulating their proliferation [39]. Enhanced neurogenesis by stimulation of neural stem/progenitor cell proliferation is naturally observed during exercises [30]. Exercises elevate reactive oxygen species formation, and polyphenols including curcumin can promote the nuclear factor-erythroid 2-related factor 2 (Nrf2) antioxidant response [30]. Therefore, altered redox balance in the hippocampus is believed to trigger neural stem/progenitor cell proliferation. In addition, elevated hippocampal BDNF level is considered to be important for enhancing neurogenesis by exercises and/or curcumin [39,69]. Hippocampal BDNF 
also seems to be correlated with memory and spatial learning, since a polyphenol-rich diet has been reported to increase intensity of hippocampal neurogenesis under a persistently stressful situation by increasing the hippocampal BDNF amount and CREB expression $[16,69]$. The above data suggest that the signaling pathways of ERK and BDNF can improve neurogenic activity, which will allow the discovery of a possible therapy that stimulates hippocampal neurogenesis after birth and will be useful for the treatment of postischemic neurodegeneration with Alzheimer phenotype.

Curcumin treatment increases neurite outgrowth and proliferation of neural stem cells in persistently stressed animals and reverses memory deficits in aged rats [63]. According to Tiwari et al., [63] the molecular mechanism by which curcumin induces neurogenesis is connected with canonical Wnt/ $\beta$-catenin pathway initiation and glycogen

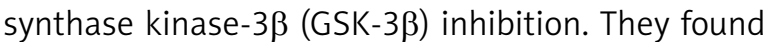
that curcumin stimulates neural stem cell proliferation and neuronal differentiation and reverses $\beta$-amyloid peptide-induced inhibition of hippocampal neurogenesis and memory deficits in an Alzheimer's disease rat model [67] through activation of the canonical Wnt/ $\beta$-catenin pathway. Curcumin activates $W n t / \beta$-catenin signaling and stimulates adult neurogenesis through interaction with Wnt inhibitor factor (Wif-1), Dickkopf (Dkk-1) and GSK-3 $\beta$.

Curcumin is an approved stimulator of hippocampal neurogenesis, but its exact role in ischemic hippocampal neurogenesis remains to be determined. In a $\beta$-amyloid peptide model of Alzheimer's disease in rat, curcumin suppressed glial activity and enhanced spatial memory [67]. It is probable that by downregulation of glial activity, curcumin protects hippocampal neurogenesis and improves cognitive deficits in neurodegenerative disorders such as postischemic injury [5]. Apart from the above-mentioned prevention of glial activity, curcumin might act by upregulation of serotonin receptor $1 \mathrm{~A}$ and BDNF, and via activation of extracellular signal-regulated kinases and p38 MAPKs [30,39]. Both pathways are involved in the modification of neuronal plasticity. Moreover, curcumin might influence neurogenesis by affecting genes, including histone acetyltransferases and histone deacetylases, among them sirtuin 1 (SIRT1) (Table I) $[8,56]$.

A recent investigation demonstrated that longterm administration of curcumin stimulated hippo- campal neurogenesis and improved cognition in aged rats [12]. The gene responses in the hippocampus and cortex of the aged rats suggest a beneficial role of prolonged treatment by curcumin in modifying the neuronal network that influences synaptic plasticity and cell growth [12]. Curcumin did not affect induction of anxiety, locomotor activity and/or improvement of physical body strength, but affected non-spatial and spatial memory in aged rats [10, 12]. Prolonged treatment with curcumin increases neurogenesis in both the subgranular zone of the dentate gyrus and the hilus of the hippocampus. Data suggest a beneficial role of long-term treatment by curcumin in improving memory and learning by the induction of neurogenesis in the dentate gyrus.

Prolonged treatment with curcumin positively influences the aged rat's gene dysregulation in the hippocampus and cortex, and this phenomenon was larger in the cortex than in the hippocampus [12]. It was noted that the amount of upregulated genes decreased in the hippocampus but it increased in the cortex with time of treatment with curcumin. One important finding of the genetic investigation is that the majority of those differentially expressed genes have implications in brain development and memory and are involved in hippocampal neurogenesis [12]. The NeuroD1 gene, which was overexpressed in the cortex, is downstream of the Wnt pathway and is very important for the neurogenesis and survival of neuronal progenitors [12]. Cortical upregulation of the Fezf2 gene after curcumin treatment was noted, and this gene has been involved in neurogenesis and growth of subcortical projection neuronal cells. Next the Wnt2 gene was overexpressed in the adult hippocampus and has been implicated in neurogenesis, dendrite growth and arborization. Long-term treatment with curcumin upregulated the Tiam 1 gene, which is vital for neurite outgrowth and for dendrite spine morphogenesis. It is interesting that curcumin upregulated in the hippocampus genes associated with neurotransmission such as synaptotagmin 9 (Syt9) [12]. The physiological role of Syt9 in synaptic neurotransmission, plasticity and memory is currently not clear. Earlier investigations demonstrated that other synaptotagmin genes such as Syt1 and Syt4 are closely associated with associative and spatial memory. Dong et al. [12] found overexpression of neurotransmission genes such as syntaxin 1a (Stx1a) and complexin 3 (Cplx3) in 
Table I. Summary of the potential positive health effects of curcumin according to human and animal model studies

\begin{tabular}{|c|c|c|}
\hline No. & Health benefits & References \\
\hline 1. & $\begin{array}{l}\text { Antioxidant activity } \\
\text { - Modulation of Nrf2 signaling pathway }\end{array}$ & {$[12,13,16,19,30,34,62,63]$} \\
\hline 2. & $\begin{array}{l}\text { Anti-inflammatory activity } \\
\text { - Inhibition of nuclear factor } \kappa B\end{array}$ & {$[12,13,16,19,34,62]$} \\
\hline 3. & Neurogenesis improvement & {$[8,12,30,39,56,63,69]$} \\
\hline 4. & Neuroprotection & {$[13,34,62,63,66,73,74,75]$} \\
\hline 5. & Excitotoxicity protection & [13] \\
\hline 6. & Mitochondrial dysfunction reduction & [13] \\
\hline 7. & Neuronal apoptosis inhibition & {$[13,66,74,75]$} \\
\hline 8. & Brain edema protection & {$[13,20]$} \\
\hline 9. & Blood-brain barrier protection & {$[13,75]$} \\
\hline 10. & $\beta$-amyloid peptide plaque reduction & {$[12,13,34,62]$} \\
\hline 11. & $\beta$-amyloid peptide concentration reduction & {$[13,19,34,62]$} \\
\hline 12. & $\beta$-amyloid peptide inhibition of extracellular aggregation & {$[13,34,62,63]$} \\
\hline 13. & $\begin{array}{l}\text { Amyloid precursor protein maturation inhibition and suppression of } \beta \text {-amyloid peptide } \\
\text { production }\end{array}$ & {$[13,34,62]$} \\
\hline 14. & $\beta$-amyloid peptide clearance increase & [13] \\
\hline 15. & $\tau$-protein phosphorylation inhibition & {$[19,34,62,63]$} \\
\hline 16. & Soluble $\tau$-protein reduction & {$[34]$} \\
\hline 17. & Soluble $\tau$-protein increase clearance & [34] \\
\hline 18. & Microglia and astrocyte activity inhibition & {$[5,67]$} \\
\hline 19. & $\begin{array}{l}\text { Overexpression of genes involved in neurotransmission, signal transduction, metabolism } \\
\text { and neural development } \\
\text { - Reelin, Nestin, Pax6, Neurogenin, NeuroD1, Nuroregulin, Neuroligin, Stat3, Syt9, Stx1a, } \\
\text { Cplx3, Fezf2, NeuroD6, Adcyl1, Kit, Htr2c, LPL, Wnt2, Nnat, Tiam1, Unc5d, Shank3, Htr2a, } \\
\text { Cip98, CD74, Snip, Wee1, Cav1, Nlgn2, Sirt1 }\end{array}$ & {$[8,12,56,63]$} \\
\hline 20. & Cognition improvement & {$[5,12,13,16,19,63,66,67,75]$} \\
\hline 21. & Anticarcinogenic activity & {$[13,39,69]$} \\
\hline
\end{tabular}

the cortex following curcumin treatment. The above genes influence neurotransmission and are strongly associated with synaptic plasticity and memory. Other synaptic transmission and memory formation genes were upregulated in the hippocampus such as adenylyl cyclase 1 (Adcyl1), LPL and Kit and in the cortex Cip98, Shank3, Snip and Nlgn2. In summary, the above data suggest that the curcumin upregulated genes in the hippocampus and cortex may be a factor responsible for the improvement of cognition activity in aged rats [12]. Dong et al. [12] additionally noted overexpression of the CD74 gene in the cortex of aged animals after prolonged treatment with curcumin. The CD74 gene is important in Alzheimer's disease neuropathology and cooperates together with amyloid precursor protein and finally reduces $\beta$-amyloid peptide generation. The study of upregulated genes after curcumin administration suggested that these genes are important for neurotransmission, synaptic plasticity, neurogenesis and memory creation. 


\section{Potent neuroprotective activity of curcumin}

Nowadays curcumin has been intensively studied as a promising therapeutic for postischemic neurodegeneration with Alzheimer phenotype. Evidence indicates that curcumin may act as a neuroprotective substance on postischemic outcome and behavioral deficits in rodents and this neuroprotective effect is presented by antiapoptotic action $[66,74,75]$. Other studies have shown that curcumin reverses the permeability of the ischemic blood-brain barrier and decreases brain edema $[13,20]$. Additionally in behavioral studies in rodents curcumin reverses cognitive changes [13]. Curcumin by stimulation of protein kinase $C$ activity decreases NMDA receptor function. Curcumin has been shown to decrease the calcium-dependent induction of caspases [13]. Curcumin inhibits nNOS activity and protects against peroxynitrite-induced neuronal cell death in vitro. Additionally, Esatbeyoglu et al. [13] showed that curcumin inhibits hydrogen peroxide triggered neurotoxicity in Neuro2-A cells. In summary, curcumin presents anti-amyloid, anti-tau protein hyperphosphorylation, antioxidative and anti-inflammatory actions, and it has been proposed that curcumin might be neuroprotective in brain ischemia neurodegeneration (Table I) [34,62]. As a consequence of curcumin's beneficial health potential, including anti-inflammatory, antioxidative and anti-excitotoxic activities, it may be considered as a promising substance in the treatment of postischemic brain neurodegeneration with Alzheimer phenotype (Table I).

Curcumin lowers amyloid deposits and inhibits tau protein aggregation in a transgenic model of Alzheimer's disease and reduces oxidative injury, neuroinflammatory response, as well as cognitive deficit after infusion of amyloid into the brain [19]. Experimental models show that curcumin reduces neuroinflammation, oxidative stress and the density of $\beta$-amyloid peptide plaques and soluble $\beta$-amyloid peptide level in the brain tissue both in vitro and in vivo $[12,13]$. Curcumin prevents the aggregation of $\beta$-amyloid peptide in vitro and supports the clearance of $\beta$-amyloid peptide aggregates. Curcumin inhibits the maturation of amyloid precursor protein and stops the generation of $\beta$-amyloid peptide in vitro [13]. Curcumin reduced soluble tau protein and elevated heat shock protein involved in tau protein clearance, showing that even after tangles have been formed, tau protein-dependent behavioral and synaptic deficits could be reversed [34].

Curcumin neuroprotection activity was noted in experimental models of Parkinson's, Huntington's and Alzheimer's disease and multiple sclerosis [63]. Curcumin acts by its antioxidant activity and by inducing the transcription factor Nrf2, a regulator of antioxidant stress [63]. It was shown that curcumin inhibits $\beta$-amyloid peptide oligomerization and $\tau$-protein phosphorylation in the brain tissue [63]. On the whole, curcumin research indicates its possible neuroprotective function.

Additionally, some investigations have indicated anticarcinogenic action of curcumin. It has been shown that curcumin exerts its potential anticarcinogenic activities by regulating the tumor suppressor gene p53 and a variety of transcription factors, e.g. Nrf2 and NFKB, by modifying inflammatory signaling and by triggering apoptosis (Table I) [13].

\section{Conclusions}

Every mammal has stem cells in different organs, being particularly important in the brain, and nowadays these cells are believed to play a role in cell substitute after birth [23]. The existence of neural stem/ progenitor cells in the mammalian mature brain that are capable of forming new neurons continues to push the developments of new approaches to brain repair after ischemia. In particular, the modulation of impaired neurogenesis in the hippocampus is associated with the amelioration of cognitive deficits and better outcomes related to brain ischemia (Table I) $[66,75]$. Therefore, the latest focus has been concentrated on the development of new natural drugs that can simulate proliferation of ischemic neural stem/ progenitor cells after birth. The mechanisms and factors that control the formation of new neurons in the animal and human brain after ischemia are by and large unknown, and finding such factors is likely to lead to new ways of treating brain ischemia $[10,58]$. This review presents the neurogenic and neuroprotective properties of curcumin and provides a new basis for a possible reparative strategy whereby endogenous neural stem/progenitor cells are recruited by dietary stimulation to address ischemic neuronal loss $[1,39]$. Curcumin improves the survival rate of newly generated neurons and stimulates impaired neurogenesis after ischemia by elevation of neurotrophic factors $[30,39]$. However, curcumin triggers the mitogenic property of neural stem/ 
progenitor cells and stimulates their proliferation by BDNF and MAP kinase activation $[30,39]$. Collectively, understanding the neurogenic mechanisms after ischemia and curcumin neurogenic activity could provide a neurorestorative strategy that stimulates dysregulated endogenous neural stem/progenitor cell activity and as a result prevents neuropathological changes and neurological deficits after ischemia. There are, however, some encouraging results suggesting that curcumin could be of therapeutic relevance in these kinds of diseases (Table I) $[12,13,23,63]$. Amid all the optimism surrounding the potential of ischemia-induced neurogenesis, there remain a variety of significant concerns. Postischemic epilepsy is a fairly common morbidity after an ischemic episode [22]. It has been suggested that aberrant neurogenesis triggers the epileptic activity [22]. Clearly any research aimed at enhancing neurogenesis might result in this and other unwanted side effects. In addition, enhanced neurogenesis would stimulate cell growth; it is possible that increased proliferation could result in tumor development [22]. In this situation many issues regarding specificity, mechanism and potential toxicity need to be more carefully studied before clinical trials can occur $[13,23]$. Undoubtedly, more investigations are needed to explore hippocampal neurogenesis and the effects of curcumin in long-term natural interventions [12], and the fact that curcumin seems to be innocuous in animals and humans could prompt additional studies on the effect of curcumin in the onset and progression of postischemic brain neurodegeneration with Alzheimer phenotype. Our review also points out the limitations of available data and potential directions of research into the role of curcumin in hippocampal neurogenesis and neuroprotection in ischemic brain neurodegeneration with Alzheimer phenotype course.

\section{Acknowledgments}

The authors acknowledge support by the Polish National Science Centre (DEC-2013/09/B/NZ7/ 01345-RP,ABK,MUK,SJ,JK) and by the Mossakowski Medical Research Centre, Polish Academy of Sciences, Poland (T3-RP). The paper was developed using equipment purchased within the Project "The equipment of innovative laboratories doing research on new medicines used in the therapy of civilization and neoplastic diseases" within the Operation Pro- gram Development of Eastern Poland 2007-2013, Priority Axis I Modern Economy, Operations I.3 Innovation Promotion (JK).

\section{Disclosure}

Authors report no conflict of interest.

\section{References}

1. Albarracin SL, Stab B, Casas Z, Sutachan JJ, Samudio I, Gonzalez J, Gonzalo L, Capani F, Morales L, Barreto GE. Effects of natural antioxidants in neurodegenerative diseases. Nutr Neurosci 2012; 15: 1-9.

2. Allen E. The cessation of mitosis in the central nervous system of the albino rat. J Comp Neurol 1912; 22: 547-568.

3. Barra de la Tremblaye P, Plamondon H. Impaired conditioned emotional response and object recognition are concomitant to neuronal damage in the amygdale and perirhinal cortex in middle-aged ischemic rats. Behav Brain Res 2011; 219: 227-233.

4. Basli A, Soulet S, Chaher N, Mérillon JM, Chibane M, Monti JP, Richard T. Wine polyphenols: potential agents in neuroprotection. Oxid Med Cell Longev 2012; Article ID 805762.

5. Biscaro B, Lindvall O, Tesco G, Ekdahl CT, Nitsch RM. Inhibition of microglial activation protects hippocampal neurogenesis and improves cognitive deficits in a transgenic mouse model for Alzheimer's disease. Neurodegener Dis 2012; 9: 187-198.

6. Burbach GJ, Hellweg R, Haas CA, Del Turco D, Deicke U, Abramowski D, Jucker M, Staufenbiel M, Deller T. Induction of brain-derived neurotrophic factor in plaque associated glial cells of aged APP23 transgenic mice. J Neurosci 2004; 24: 24212430.

7. Choi SH, Veeraraghavalu K, Lazarov O, Marler S, Ransohoff RM, Ramirez JM, Sisodia SS. Non-cell autonomous effects of presenilin 1 variants on enrichment mediated hippocampal progenitor cell proliferation and differentiation. Neuron 2008; 59 : 568-580.

8. Chung S, Yao H, Caito S, Hwang JW, Arunachalam G, Rahman I. Regulation of SIRT1 in cellular functions: Role of polyphenols. Arch Biochem Biophys 2010; 501: 79-90.

9. Curtis MA, Kam M, Nannmark U, Anderson MF, Axell MZ, Wikkelso C, Holtås S, van Roon-Mom WM, Björk-Eriksson T, Nordborg C, Frisén J, Dragunow M, Faull RL, Eriksson PS. Human neuroblasts migrate to the olfactory bulb via a lateral ventricular extension. Science 2007; 315: 1243-1249.

10. Deng W, Aimone JB, Gage FH. New neurons and new memories: how does adult hippocampal neurogenesis affect learning and memory? Nat Rev Neurosci 2010; 11: 339-350.

11. Dias GP, Cavegn N, Nix A, Do Nascimento Bevilaqua MC, Stangl D, Zainuddin MS, Nardi AE, Gardino PF, Thuret S. The role of dietary polyphenols on adult hippocampal neurogenesis: Molecular mechanisms and behavioural effects on depression and anxiety. Oxid Med Cell Longev 2012; 2012: 541971.

12. Dong S, Zeng Q, Mitchell ES, Xiu J, Duan Y, Li Ch, Tiwari JK, Hu Y, Cao X, Zhao Z. Curcumin enhances neurogenesis and cognition in aged rats: Implications for transcriptional interactions related to growth and synaptic plasticity. PLos ONE 2012; 7: e31211. 
13. Estabeyoglu T, Huebbe P, Ernst IMA, Chin D, Wagner AE, Rimbach $\mathrm{G}$. Curcumin-From molecule to biological function. Angew Rev Int Ed 2012; 51: 5308-5332.

14. Faria A, Pestana D, Teixeira D, Azevedo J, De Freitas V, Mateus N, Calhau C. Flavonoid transport across RBE4 cells: a blood-brain barrier model. Cell Mol Biol Lett 2010; 15: 234-241.

15. Flynn RWV, MacWalter RSM, Doney ASF. The cost of cerebral ischemia. Neuropharmacology 2008; 55: 250-256.

16. Frautschy SA, Hu W, Kim P, Miller SA, Chu T, Harris-White ME, Cole GM. Phenolic anti-inflammatory antioxidant reversal of Abeta-induced cognitive deficits and neuropathology. Neurobiol Aging 2001; 22: 993-1005.

17. Haile WB, Wu J, Echeverry R, Wu F, An J, Yepes M. Tissue type plasminogen activator has a neuroprotective effect in the ischemic brain mediated by neuronal TNF- $\alpha$. JCBFM 2012; 32 57-59.

18. Hung CW, Chen YC, Hsieh WL, Chiou SH, Kao CL. Ageing and neurodegenerative diseases. Ageing Res Rev 2010; 9: S36-S46.

19. Ishrat T, Hoda MN, Khan MB, Yousuf S, Ahmad M, Khan MM, Ahmad A, Islam F. Amelioration of cognitive deficits and neurodegeneration by curcumin in rat model of sporadic dementia of Alzheimer's type (SDAT). Eur Neuropsychopharm 2009; 19 636-647.

20. Jiang J, Wang W, Sun YJ, Hu M, Li F, Zhu DY. Neuroprotective effect of curcumin on focal cerebral ischemic rats by preventing blood-brain barrier damage. Eur J Pharmacol 2007; 561: 54-62.

21. Jones QR, Warford J, Rupasinghe HPV, Robertson GS. Target-based selection of flavonoids for neurodegenerative disorders. Trends Pharmacol Sci 2012; 33: 602-610.

22. Kernie SG, Parent JM. Forebrain neurogenesis after focal ischemic and traumatic brain injury. Neurobiol Dis 2010; 37: 267-274.

23. Kim SJ, Son TG, Park HR, Park M, Kim M-S, Kim HS, Chung HY, Mattson MP, Lee J. Curcumin stimulates proliferation of embry onic neuronal progenitor cells and neurogenesis in the adult hippocampus. J Biol Chem 2008; 283: 14497-14505.

24. Kiryk A, Pluta R, Figiel I, Mikosz M, Ułamek M, Niewiadomska G, Jabłoński M, Kaczmarek L. Transient brain ischemia due to cardiac arrest causes irreversible long-lasting cognitive injury. Behav Brain Res 2011; 219: 1-7.

25. Knoth R, Singec I, Ditter M, Pantazis G, Capetian P, Meyer RP Horvat V, Volk B, Kempermann G. Murine features of neurogenesis in the human hippocampus across the lifespan from 0 to 100 years. PLoS One 2010; 5: e8809.

26. Kuhn HG, Dickinson-Anson H, Gage FH. Neurogenesis in the dentate gyrus of the adult rat: Age-related decrease of neuronal progenitor proliferation. J Neurosci 1996; 16: 2027-2033.

27. Lazarov O, Marr RA. Neurogenesis and Alzheimer's disease: At the crossroads. Exp Neurol 2010; 223: 267-281.

28. Leys D, Henon H, Mackowiak-Cordoliani MA, Pasquier F. Post stroke dementia. Lancet Neurol 2005; 4: 752-759.

29. Li J, Wang YJ, Zhang M, Fang CQ, Zhou HD. Cerebral ischemia aggravates cognitive impairment in a rat model of Alzheimer's disease. Life Sci 2011; 89: 86-92.

30. Lichtenwalner RJ, Parent JM. Adult neurogenesis and the ischemic forebrain. JCBFM 2006; 26: 1-20.

31. Lindvall O, Kokaia Z. Stem cell research in stroke: how far from the clinic? Stroke 2011; 42: 2369-2375.
32. Lopez-Toledano MA, Ali Faghihi M, Patel NS, Wahlestedt C. Adult neurogenesis: A potential tool for early diagnosis in Alzheimer's disease? J Alzheimers Dis 2010; 20: 395-408.

33. Luheshi NM, Kovacs KJ, Lopez-Castejon G, Brough D, Denes A. Interleukin- $1 \alpha$ expression precedes IL-1 $\beta$ after ischemic brain injury and is localized to area of focal neuronal loss and penumbral tissues. J Neuroinflamm 2011; 29: 186.

34. Ma QL, Zuo X, Yang F, Ubeda OJ, Gant DJ, Alaverdyan M, Teng E, Hu S, Chen PP, Maiti P, Teter B, Cole GM, Frautschy SA. Curcumin suppresses soluble tau dimers and corrects molecular chaperone, synaptic, and behavioral deficits in aged human tau transgenic mice. J Biol Chem 2013; 288: 4056-4065.

35. Menezea AR, Lavie CJ, Milani RV, Okeefe J. The effects of statins on prevention of stroke and dementia: a review. Psychosomatics 2012; 32: 240-249.

36. Molina CA. Reperfusion therapies for acute ischemic stroke: current pharmacological and mechanical approaches. Stroke 2011; 42: 16-19.

37. Olesen J, Gustavsson A, Svensson M, Wittchen HU, Jonsson B. The economic cost of brain disorders in Europe. Eur J Neurol 2012; 19: 155-162.

38. Paizanis E, Kelai S, Renoir T, Hamon M, Lanfumey L. Life-long hippocampal neurogenesis: Environmental, pharmacological and neurochemical modulations. Neurochem Res 2007; 32: 1762-1771.

39. Park HR, Lee J. Neurogenic contributions made by dietary regulation to hippocampal neurogenesis. Ann N Y Acad Sci 2011; 1229: 23-28.

40. Perez-Jimenez J, Neveu V, Vos F, Scalbert A. Identification of the 100 richest dietary sources of polyphenols: an application of the Phenol-Explorer database. Eur J Clin Nutr 2010; 64: 112-120.

41. Pinkston JB, Alekseeva N, Gonzalez Toledo E. Stroke and dementia. Neurol Res 2009; 31: 824-831.

42. Pluta R. Influence of prostacyclin on early morphological changes in the rabbit brain after complete 20-min ischemia. J Neurol Sci 1985; 70: 305-316.

43. Pluta R. Astroglial expression of the beta-amyloid in ischemia reperfusion brain injury. Ann N Y Acad Sci 2002; 977: 102-108.

44. Pluta R, Ułamek M, Januszewski S. Micro-blood-brain barrier openings and cytotoxic fragments of amyloid precursor protein accumulation in white matter after ischemic brain injury in long-lived rats. Acta Neurochir (Suppl) 2006; 96: 267-271.

45. Pluta R, Januszewski S, Ułamek M. Ischemic blood-brain barrier and amyloid in white matter as etiological factors in leukoaraiosis. Acta Neurochir (Suppl) 2008; 102: 353-356.

46. Pluta R, Ułamek M, Jabłoński M. Alzheimer's mechanisms in ischemic brain degeneration. Anat Rec 2009; 292: 1863-1881.

47. Pluta R, Januszewski S, Jabłoński M, Ułamek M. Factors in creepy delayed neuronal death in hippocampus following brain ischemia-reperfusion injury with long-term survival. Acta Neurochir (Suppl) 2010; 106: 37-41.

48. Pluta R, Ułamek M, Jabłoński M. Consideration of the ischaemic basis and treatment of Alzheimer's disease. Folia Neuropathol 2010; 48: 11-26.

49. Pluta R, Furmaga-Jabłońska W, Jabłoński M. Therapeutic food benefits after ischemic brain edema. Nutrition 2012; 28: 11921193. 
50. Pluta R, Jabłoński M, Czuczwar SJ. Postischemic dementia with Alzheimer phenotype: selectively vulnerable versus resistant areas of the brain and neurodegeneration versus $\beta$-amyloid peptide. Folia Neuropathol 2012; 50: 101-109.

51. Pluta R, Kocki J, Maciejewski R, Ułamek-Kozioł M, Jabłoński M, Bogucka-Kocka A, Czuczwar SJ. Ischemia signaling to Alzheimer-related genes. Folia Neuropathol 2012; 50: 322-329.

52. Pluta R, Furmaga-Jabłońska W, Maciejewski R, Ułamek-Kozioł M, Jabłoński M. Brain ischemia activates $\beta$ - and $\gamma$-secretase cleavage of amyloid precursor protein: Significance in sporadic Alzheimer's disease. Mol Neurobiol 2013; 47: 425-434.

53. Pluta R, Jabłoński M, Ułamek-Kozioł M, Kocki J, Brzozowska J, Januszewski S, Furmaga-Jabłońska W, Bogucka-Kocka A, Maciejewski R, Czuczwar SJ. Sporadic Alzheimer's disease begins as episodes of brain ischemia and ischemically dysregulated $\mathrm{Alz}$ heimer's disease genes. Mol Neurobiol 2013; 48: 500-515.

54. Popa-Wagner A, Buga AM, Kokaia Z. Perturbed cellular response to brain injury during aging. Ageing Res Rev 2011; 10: 71-79.

55. Qi J, Wu H, Yang Y, Wand D, Chen Y, Gu Y, Liu T. Cerebral ischemia and Alzheimer's disease: the expression of amyloid- $\beta$ and apolipoprotein E in human hippocampus. J Alzheimers Dis 2007; 12: 335-341.

56. Reuter S, Gupta SC, Park B, Goel A, Aggarwal BB. Epigenetic changes induced by curcumin and other natural compounds. Genes Nutr 2011; 6: 93-108.

57. Saver JL. Time is brain - quantified. Stroke 2006; 37: 263-266.

58. Sekeljic V, Bataveljic D, Stamenkovic S, Ułamek M, Jabłoński M, Radenovic L, Pluta R, Andjus PR. Cellular markers of neuroinflammation and neurogenesis after ischemic brain injury in the longterm survival rat model. Brain Struct Funct 2012; 217: 411-420.

59. Stangl D, Thuret S. Impact of diet on adult hippocampal neurogenesis. Genes Nutr 2009; 4: 271-282.

60. Tarkowski E, Issa R, Sjogren M, Wallin A, Blennow K, Tarkowski A, Kumar P. Increased intrathecal levels of the angiogenic factors VEGF and TGF-beta in Alzheimer's disease and vascular dementia. Neurobiol Aging 2002; 23: 237-243.

61. Thilakarathna SH, Rupasinghe HPV, Needs APW. Apple peel bioactive rich extracts effectively inhibit in vitro human LDL oxidation. Food Chem 2013; 138: 463-470.

62. Thiyagarajan M, Sharma SS. Neuroprotective effect of curcumin in middle cerebral artery occlusion induced focal cerebral ischemia in rats. Life Sci 2004; 74: 969-985.

63. Tiwari SK, Agrawal S, Seth B, Yadav A, Nair S, Bhatnagar P, Karmakar M, Kumari M, Chauhan LKS, Patel DK, Srivastava V, Singh D, Gupta SK, Tripathi A, Chaturvedi RK, Gupta KCh. Curcumin-loaded nanoparticles potently induce adult neurogenesis and reverse cognitive deficits in Alzheimer's disease model via canonical Wnt/ $\beta$-catenin pathway. ACSNANO 2014 8: 76-103.

64. Tuttolomondo A, Di Raimondo D, Di Sciacca R, Pinto A, Licata G. Inflammatory cytokines in acute ischemic stroke. Curr Pharm Design 2008; 14: 3574-3589.

65. Ułamek-Kozioł M, Furmaga-Jabłońska W, Januszewski S, Brzozowska J, Ściślewska M, Jabłoński M, Pluta R. Neuronal autophagy: self-eating or self-cannibalism in Alzheimer's disease. Neurochm Res 2013; 38: 1769-1773.
66. Wang Q, Sun AY, Simonyi A, Jensen M, Shelat PB, Rottinghaus GE, MacDonald RS, Miller DK, Lubahn DE, Weisman GA, Sun GY. Neuroprtective mechanisms of curcumin against cerebral ischemia-induced neuronal apoptosis and behavioral deficits. J Neurosci Res 2005; 82: 138-148.

67. Wang Y, Yin H, Wang L, Shuboy A, Lou J, Han B, Zhang X, Li J. Curcumin as a potential treatment for Alzheimer's disease: A study of the effects of curcumin on hippocampal expression of glial fibrillary acidic protein. Am J Chin Med 2013; 41: 59-70.

68. Wen Y, Yang SH, Liu R, Perez EJ, Brun-Ziukemagel AM, Koulen P, Simpkins JW. Cdk5 is involved in NFT-like tauopathy induced by transient cerebral ischemia in female rats. Biochim Biophys Acta 2007; 1772: 473-483.

69. Xu Y, Ku B, Cui L, Li X, Barish PA, Foster TC, Ogle WO. Curcumin reverses impaired hippocampal neurogenesis and increases serotonin receptor $1 \mathrm{~A}$ mRNA and brain-derived neurotrophic factor expression in chronically stressed rats. Brain Res 2007; 1162: 9-18.

70. Yang SH, Simpkins JW. Ischemia-reperfusion promotes tau and beta-amyloid pathology and a progressive cognitive impairment. In Pluta R, editor. Ischemia-reperfusion pathways in Alzheimer's disease. Nova Science Publishers, Inc., New York 2007, pp. 113-138.

71. Zainuddin MSA, Thuret S. Nutrition, adult hippocampal neurogenesis and mental health. Br Med Bull 2012; 103: 89-114.

72. Zhang W, Potrovita I, Tarabin V, Herrmann O, Beer V, Weih F, Schneider A, Schwaninger M. Neuronal activation of NF- $\kappa B$ contributes to cell death in cerebral ischemia. JCBFM 2005; 25 : 30-40.

73. Zhao C, Deng W, Gage FH. Mechanisms and functional implications of adult neurogenesis. Cell 2008; 132: 645-660.

74. Zhao J, Zhao Y, Zheng W, Lu Y, Feng G, Yu S. Neuroprotective effect of curcumin on transient focal cerebral ischemia in rats. Brain Res 2008; 1229: 224-232.

75. Zhao J, Yu S, Zheng W, Feng G, Luo G, Wang L, Zhao Y. Curcumin improves outcomes and attenuates focal cerebral ischemic injury via antiapoptotic mechanisms in rats. Neurochem Res 2010; 35: 374-379.

76. Zheng M, Liu J, Ruan Z, Tian S, Ma Y, Zhu J, Li G. Intrahippocampal injection of Abeta(1-42) inhibits neurogenesis and down-regulates IFN-gamma and NF-kappaB expression in hippocampus of adult mouse brain. Amyloid 2013; 20: 13-20.

77. Zhu DY, Lau L, Wei JS, Liu SH, Lu YM. Activation of CAMP-respose-element-binding protein (CREB) after focal cerebral ischemia stimulates neurogenesis in the adult dentate gyrus. Proc Natl Acad Sci USA 2004; 101: 9453-9457. 